\title{
Oxidative Stress as a Potential Target in Acute Kidney Injury
}

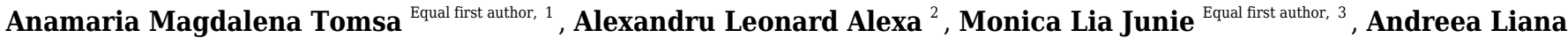 \\ Rachisan $^{\text {Corresp., } 1 \text {, Lorena Ciumarnean }}{ }^{4}$ \\ ${ }^{1}$ Department of Pediatrics II, University of Medicine and Pharmacy of Cluj-Napoca, Cluj-Napoca, Romania \\ 2 Department of Anesthesia and Intensive Care I, University of Medicine and Pharmacy of Cluj-Napoca, Cluj-Napoca, Romania \\ 3 Department of Microbiology, University of Medicine and Pharmacy of Cluj-Napoca, Cluj-Napoca, Romania \\ 4 Department of Internal Medicine IV, University of Medicine and Pharmacy of Cluj-Napoca, Cluj-Napoca, Romania \\ Corresponding Author: Andreea Liana Rachisan \\ Email address: andreea_rachisan@yahoo.com
}

Background Acute kidney injury (AKI) is a major problem for health systems being directly related to short and long-term morbidity and mortality. In the last years, the incidence of AKI has been increasing. AKI and chronic kidney disease (CKD) are closely interconnected, with a growing rate of CKD linked to repeated and severe episodes of AKI. AKI and CKD can occur also secondary to imbalanced oxidative stress reactions, inflammation and apoptosis. The kidney is particularly sensitive to oxidative stress (OS). OS is known as a crucial pathogenetic factor in cellular damage, with a direct role in initiation, development and progression of AKI. The aim of thisreview is to focus on the pathogenetic role of OS in AKI in order to gain a better understanding. We exposed the potential relationships between OS and the perturbation of renal function and we also presented the redoxdependent factors that can contribute to early kidney injury. In the last decades, promising advances have been made in understanding the pathophysiology of AKI and its consequences, but more studies are needed in order to develop new therapies that can address OS and oxidative damage in early stages of AKI. 
1 Oxidative Stress as a Potential Target in Acute Kidney

2 Injury

3 Anamaria Magdalena Tomsa ${ }^{1}$, Alexandru Leonard Alexa ${ }^{2}$, Lia Monica Junie ${ }^{3}$, Andreea Liana

4 Rachisan $^{1}$, Lorena Ciumarnean ${ }^{4}$

5

$6 \quad{ }^{1}$ Department of Pediatrics II, University of Medicine and Pharmacy Cluj-Napoca, Romania

$7 \quad 2$ Department of Anesthesia and Intensive Care I, University of Medicine and Pharmacy Cluj-

8 Napoca, Romania

$9{ }^{3}$ Department of Microbiology, Iuliu Hatieganu University of Medicine and Pharmacy Cluj-

10 Napoca, Romania

$11{ }^{4}$ Department of Internal Medicine IV, University of Medicine and Pharmacy Cluj-Napoca,

12 Romania

13

14

Corresponding Author:

Andreea Liana Rachisan

3 Crisan Street, Cluj-Napoca, Cluj, Romania

Email address: andreea_rachisan@yahoo.com

\section{Abstract}

\section{Background}

Acute kidney injury (AKI) is a major problem for health systems being directly related to short and long-term morbidity and mortality. In the last years, the incidence of AKI has been increasing. AKI and chronic kidney disease (CKD) are closely interconnected, with a growing rate of CKD linked to repeated and severe episodes of AKI. AKI and CKD can occur also secondary to imbalanced oxidative stress reactions, inflammation and apoptosis. The kidney is particularly sensitive to oxidative stress (OS). OS is known as a crucial pathogenetic factor in cellular damage, with a direct role in initiation, development and progression of AKI. The aim of this review is to focus on the pathogenetic role of OS in AKI in order to gain a better understanding. We exposed the potential relationships between OS and the perturbation of renal function and we also presented the redox-dependent factors that can contribute to early kidney injury. In the last decades, promising advances have been made in understanding the pathophysiology of AKI and its consequences, but more studies are needed in order to develop new therapies that can address OS and oxidative damage in early stages of AKI.

\section{Methods}

We searched PubMed for relevant articles published up to May 2019. In this review we incorporated data from different types of studies, including observational and experimental, both in vivo and in vitro, studies that provided information about oxidative stress in the pathophysiology of AKI. 


\section{Results}

The results show that oxidative stress plays a major key role in the initiation and development of AKI, providing the chance to find new targets that can be therapeutically addressed.

\section{Discussion}

AKI represents a major health issue that is still not fully understood. Research in this area still provides new useful data that can help obtain a better management of the patient. Oxidative stress represents a major focus point in many studies, and a better understanding of its implications in AKI might offer the chance to fight new therapeutic strategies.

\section{Introduction}

Acute kidney injury (AKI) represents a syndrome in which the renal function deteriorates due to a sudden drop in the glomerular filtration rate. Traditionally, it has been viewed in an anatomical context (prerenal, intrarenal, and postrenal), while at the same time it has been considered to rarely transition to chronic kidney disease (CKD) ${ }^{1}$. Nowadays, the emphasis has been put on an improved understanding of AKI and its pathophysiological mechanisms, as it is considered a major risk factor for developing CKD. The fact that each episode of AKI significantly influences the outcome and accelerates the development of CKD, while a patient who suffers from CKD is more predisposed to suffer new episodes of AKI, has led to the idea that these entities, previously considered independent from each other, actually represent an interconnected syndrome ${ }^{1,2}$.

Up until recently, the real incidence of AKI was not known due to the fact that there was no consensus on what AKI actually represents. The lack of a standard definition for AKI led to different approaches to these patients, with each medical center using its own definition for $\mathrm{AKI}^{3}$. In 2004 the first standard definition was created, based on the RIFLE criteria (Risk, Injury, Failure, Loss, End-stage kidney disease) by the Second International Consensus Conference of the Acute Dialysis Quality Initiative (ADQI) Group ${ }^{4}$. Nowadays, the reported incidence shows that this syndrome represents a major public health problem, with about 1 in 4 hospitalized patients worldwide ${ }^{5}$. The mortality rates vary by age, with $23.9 \%$ in adults and $13.8 \%$ in pediatric patients ${ }^{6}$. The severity of this syndrome in the affected patients is considered to be an independent risk factor for their outcome and mortality ${ }^{7,8}$. Emerging evidence highlights that AKI represents a major risk factor for developing CKD independent from the renal function recovery in the affected patients, even in those who seemed to have completely recover after an episode of $\mathrm{AKI}^{9,10,11}$. Recent experimental results showed that the transition from AKI to CKD may be caused by a maladaptive cellular response or by a reparative response that has been misdirected or maladaptive ${ }^{11,12,13}$. Also, oxidative stress (OS) plays a crucial role in both $\mathrm{AKI}$ and $\mathrm{CKD}$, as it has been considered a central aggravating factor $^{14,15}$. Excessive accumulation of reactive oxygen species (ROS) determines the activation of adaptive gene programs, which experimental mouse models suggest they offer insufficient protection $^{16}$. 
This review aims to summarize the current knowledge about the role that oxidative stress plays in the pathophysiology of AKI, in order to gain a better understanding of this ubiquitous pathology. New biomarkers and new therapeutic strategies are needed in order to address this syndrome, therefore a detailed knowledge about its underlying mechanisms is mandatory. At this moment, there is little data about this subject in the literature, even though OS represents a major focus point in many diseases. In this review we detailed the main sources of oxidative stress in AKI, their mechanisms of action and their effect on different cellular structures. Furthermore, we included the main antioxidants that can be found in the renal tissues and data about oxidative stress biomarkers. We address this review to nephrology residents and specialists, and to whomever wants to gain a more in-depth view in this particular subject.

\section{Survey Methodology}

We completed an electronic literature search in the PubMed database and we included pertinent articles published up to May 2019, that provided information about oxidative stress and its role in the pathophysiology of AKI. In our search we used the following terms: "acute kidney injury", "acute kidney failure", "acute kidney insufficiency" in combination with "oxidative stress", "reactive oxygen species" or "reactive nitrogen species". In order to write this review, we comprised data from numerous types of studies, including observational and experimental studies, both in vitro and in vivo, including randomized controlled ones. For the purpose of this review we used overall selected papers.

\section{Oxidative stress overview}

Oxidative stress represents a metabolic disturbance caused by the enhancement of pro-oxidants, reactive oxygen species (ROS) and/or reactive nitrogen species (RNS) which surpasses the endogenous antioxidant capacity, due to various causes. Defined for the first time in 1985 by Stahland and Sies, OS has recently been intensely studied as a regulatory element in various diseases. A free radical (FR) is defined as a species that presents a single or more unpaired electrons, and which exists autonomously ${ }^{17}$. FRs are considered essential in biological evolution as they play a major role in several biochemical reactions ${ }^{19}$. Up to this moment, oxidative stress (OS) has been proved to represent a pathogenetic factor in cardiovascular diseases, neurodegenerative diseases, cancer, aging and many others ${ }^{18,19}$. OS also represents a major factor in the development of kidney damage ${ }^{20}$, therefore it might play a crucial role in therapeutic intervention when targeted. Also, OS presents damaging effects on biomolecules such as DNA, RNA, proteins, lipids, enzymes, etc. The changes that reactive species (RS) make upon these molecules could be highlighted and used as biomarkers for OS $^{19}$.

\subsection{Are reactive species important in maintaining homeostasis?}

It is considered that reactive species are important for maintaining homeostasis when they are present in low concentrations, in certain compartments, at a certain moment. ROS and RNS are 
119

120

121

122

123

124

125

126

127

128

129

130

131

132

133

134

135

136

137

138

139

140

141

142

143

144

145

146

147

148

149

150

151

152

153

154

155

156

157

158

responsible for normal redox signaling, and therefore they represent a promotor for cell survival, growth and proliferation ${ }^{21}$.

In the kidney, the blood flow and the glomerular filtration rate are maintained at a constant level by renal autoregulation, despite all the physiological changes or pathological states that may take place in the body. Two key mechanisms are responsible for the renal autoregulation: the myogenic response and tubuloglomerular feedback. Studies show that both vasoreactivity and the myogenic response are influenced by the presence of reactive species such as nitric oxide (NO) and superoxide $\left(\mathrm{O}_{2}^{-}\right)^{22,23,24,25}$.

NO is a vasodilator factor generated by endothelial nitric oxide synthase (eNOS), and it defends the renal cells (endothelial and mesangial cells) from fibrosis and apoptosis by inducing the expression of antioxidative genes and promoting a physiological renal hemodynamics ${ }^{21}$. It is well known that NO is a major factor in modulating the myogenic response ${ }^{22}$, with numerous studies showing that inhibition of NOS decreases renal blood flow and increases the renal vascular resistance in both pressor dosages ${ }^{26,27}$ as well as in dosages that have no impact on the blood pressure ${ }^{22,28}$. Also, the infusion of NO donors (sodium nitroprusside) and NO precursors (L-arginine) seems to counteract renal vasoconstriction ${ }^{29,30}$.

Intracellularly, low levels of NO may inhibit cytochrome-c (cyt-c) oxidase, altering the generation of ROS in the mitochondria ${ }^{31}$. When ROS produced by mitochondria increase moderately, they stabilize hypoxia-inducible factor (HIF) in endothelial cells, and stimulate the nuclear factor erythroid 2-related factor $2(\mathrm{Nrf} 2)^{32,33}$. Both HIF and Nrf2 protect the renal tissues against OS, therefore ROS may exhibit renoprotective effects in certain concentrations ${ }^{21,34}$. Nrf2 represents the main regulator of the response to $\mathrm{OS}^{35}$.

Interestingly, one study that focused on the effects of endogenous $\mathrm{O}_{2}{ }^{-}$showed that it becomes a crucial factor in maintaining a physiological tone in the renal vasculature when it is induced by vascular NADPH oxidase $(\mathrm{NOX})^{36}$. This further demonstrates that reactive species might play a crucial role in maintaining homeostasis.

\subsection{What reactive species are generated in AKI?}

The main etiologies of AKI are linked to ischemia and hypoxia. Due to the decrease in the renal blood flow, the cellular nutrient and oxygen uptake is limited, leading do the development of inflammation and acute tubular necrosis ${ }^{37}$. Renal ischemia and reperfusion represent major triggers of reactive oxygen species with consequential damage in renal function and tissue integrity $^{28}$. In sepsis-induced AKI there is an extensive immune response that is responsible for renal vasoconstriction, endothelial injury, and localized hypoxia, which ultimately triggers the formation of $\operatorname{ROS}^{38}$. Further, uremia is highly associated with an increase in circulating levels of indole and carbonyl compounds, which are able to upregulate systemic $\mathrm{OS}^{52}$.

Some of the initial changes that are observed with AKI development are depletion of ATP and changes in the structure of the mitochondria, leading to alterations and dysfunction in the energetic metabolism ${ }^{29,52,55}$. Each type of renal cell presents a different number of mitochondria, which is considered to be one of the major sources of $\operatorname{ROS}^{39}$, therefore the production of ROS 
159

160

161

162

163

164

165

166

167

168

169

170

171

172

173

174

175

176

177

178

179

180

181

182

183

184

185

186

187

188

189

190

191

192

193

194

195

196

197

198

varies between the renal structures. Mitochondria is also responsible for producing molecules that counteract the $\mathrm{OS}^{19}$. In the kidney, $\mathrm{NOX}$ and the mitochondrial respiratory chain are considered to be the main sources of ROS production ${ }^{40}$.

One study evaluated the mitochondrial function, structure and redox state in rodents with induced nephrotoxic and ischemic AKI via in vivo exogenous and endogenous multi-photon imaging. The results showed changes in mitochondrial NADH levels and proton motive force, and upregulated levels of mitochondrial $\mathrm{O}_{2}$, along with disjointed mitochondria. They concluded that mitochondria represents a major source of reactive oxygen species, and that an alteration in mitochondrial function plays an important role in the early phase of renal ischemia ${ }^{41,52}$. In contrast, after gentamycin exposure, the first alterations to appear were at lysosomal level in the renal epithelium, along with anomalies in brush border cells. The mitochondrial dysfunction, with changes in morphology of the mitochondria, alterations in NADH levels, reactive species and altered proton motive force occurred later in the development of nephrotoxic acute kidney injury ${ }^{52,78}$. Mitochondria is, therefore, directly responsible for increased levels of oxidative stress in AKI.

Despite the abundance of studies conducted on this topic, the exact mechanism through which reactive species are generated in AKI remains unknown. However, OS might represent a potential therapeutic target. Table 1 summarizes the main ROS found in AKI.

The production of the superoxide anion $\mathrm{O}_{2}^{-}$is the result of the one-electron reduction of oxygen in its molecular form ${ }^{42}$. Superoxide can be generated by a large variety of oxidase enzymes, and can also be generated inside the mitochondria by components of the electron transport chain. $\mathrm{O}_{2}{ }^{-}$ is mainly transported through anion channels, therefore the diffusion across different membranes is limited. Superoxide anion is a rather selective free radical, which is able to form a non-radical $\operatorname{ROS}\left(\mathrm{H}_{2} \mathrm{O}_{2}\right)$ via dismutation. The reaction can take place spontaneously, but it can also be facilitated by enzymatic catalysis ${ }^{21}$. The presence of the superoxide anion triggers a cascade of events, as its presence leads to the generation of other ROS. $\mathrm{O}_{2}^{-}$may also be produced from xanthine by xanthine oxidase (XO), and from NADPH and NADH by various oxidase enzymes which are induced by an inflammatory response ${ }^{28}$. The most potent action of $\mathrm{O}_{2}{ }^{-}$is represented by the scavenging of NO. As the levels of superoxide anion increases, it is able to disrupt the iron-sulfur centers, and it may react with catecholamines ${ }^{21}$. Local ischemia and cytokines generated in AKI induced by sepsis activate the endothelium of the renal vasculature and recruit cells from the immune system that are able to generate $\mathrm{O}_{2}{ }^{-}$via $\mathrm{NOX}^{29}$.

Hydrogen peroxide $\left(\mathrm{H}_{2} \mathrm{O}_{2}\right)$ can be generated by dismutation but also by oxidases which are able to directly reduce the molecular oxygen. $\mathrm{H}_{2} \mathrm{O}_{2}$ diffuses across different biological membranes in a similar way to water, which makes it able to express its oxidative properties in other cellular compartments and even in other cells. Peroxides are able to react with different molecules containing iron, leading to generation of additional ROS. When peroxides react with $\mathrm{Fe}^{2+}$ they generate the hydroxyl radical $\left(\mathrm{HO}^{-}\right)$, known as the Fenton reaction. When peroxide is metabolized by specific heme peroxidase in the presence of other molecules such as chloride or nitrite, it can generate hypochlorous acid, and nitrogen dioxide ${ }^{21,66}$. 
199

200

201

202

203

204

205

206

207

208

209

210

211

212

213

214

215

216

217

218

219

220

221

222

223

224

225

226

227

228

229

230

231

232

233

234

235

236

The hydroxyl radical ( $\left.\mathrm{HO}^{-}\right)$may be generated by the Fenton reaction. This radical alters and reacts with almost every cellular component, generating additional $\operatorname{ROS}^{31}$. It produces lipid peroxidation with subsequent membrane damage and toxic compounds release, including aldehydes ${ }^{66}$.

Hypochlorous acid ( $\mathrm{HClO}$ ), a highly reactive lipid soluble molecule ${ }^{21}$, is generated by phagocyte myeloperoxidase (MPO) in inflammatory cells when local ischemia is present ${ }^{29}$, and it may react with amines, producing chloroamines.

Peroxynitrite $\left(\mathrm{ONOO}^{-}\right)$is generated when superoxide anion reacts with nitric oxide. The spontaneous decomposition of peroxynitrite generates nitrogen dioxide $\left(\mathrm{NO}_{2}\right)$. Also, $\mathrm{NO}_{2}$ is generated by heme peroxidase enzymes from the nitrate metabolism. These reactive species are able to activate a variety of signaling mechanisms by oxidizing or nitrating thiols, sometimes influencing processes that are also targeted by peroxide. When RNS react with unsaturated fatty acids (FA), the result is oxidized and nitrated FA which present a multitude of biological actions. $\mathrm{ONOO}^{-}$seems to be a major inhibitor of the mitochondrial respiration chain, irreversibly disrupting the centers of iron-sulfur ${ }^{21}$.

Nitric oxide (NO) represents a soluble gas that is able to bind to ferrous sites of heme. It is generated by NOS enzymes, and in normal amounts it is a part of physiological signaling processes: it binds to guanylate cyclase in order to regulate the production of cGMP, and it binds to cytochrome c oxidase to regulate the mitochondrial respiration. While it is mainly generated by regulating the activity of nNOS (NOS1) and eNOS (NOS3), an inflammatory status is able to induce iNOS (NOS2) expression (iNOS - inducible nitric oxide synthase; nNOS - neuronal nitric oxide synthase). This process leads to the generation of larger quantities of NO which consequently modulates the inflammatory processes. Larger levels of NO interact with bound iron, and produce NO-derived RNS that can nitrosate thiols. When the concentration of NO equalizes the levels of local antioxidant enzymes, it competes with them for the scavenging of $\mathrm{O}_{2}^{-}$, generating $\mathrm{ONOO}^{-21,66}$. However, it has been shown that when using agents to inhibit the global production of NO, including the NO production from constitutive eNOS, the effect on renal IRI was not renoprotective ${ }^{43}$.

Another study showed that mice who were deficient in iNOS were resistant to renal IRI, concluding that a constant release of NO from NOS2 could be a pathogenetic factor ${ }^{44}$. NOS 2 is constitutively expressed in the renal tissue ${ }^{45}$, underlining that NO presents a physiological role in kidney functioning ${ }^{46}$. These mechanisms may potentially contribute to the development of renal disease.

Carbonyls, nitrated lipids, and unsaturated aldehydes are just some of the toxic reactive molecules that can be generated by ROS and RNS. These molecules are able to trigger signaling processes, at low levels of OS. As the level of OS increases, these molecules promote oxidative damage and cellular death ${ }^{21,66}$. Out of all possible etiologies for AKI, two of the most common are ischemia-reperfusion injury and sepsis ${ }^{32}$. 
238

239

240

241

242

243

244

245

246

247

248

249

250

251

252

253

254

255

256

257

258

259

260

261

262

263

264

265

266

267

268

269

270

271

272

273

274

275

276

277

\section{Ischemia-reperfusion injury induced $A K I$}

Ischemia-reperfusion injury (IRI) represents a major cause of AKI, and the main cause of delayed renal graft function, and renal graft loss after kidney transplantation ${ }^{47}$. In IRI, the reperfusion phase is the crucial moment when the most IRI damage might occur. The initial event that takes place immediately after reperfusion is a sudden increase in superoxide anion production in the mitochondria which is released inside the cell, and represents the main trigger for the pathology that follows reperfusion ${ }^{48,49}$. In IRI, this mechanism plays a crucial role in initiating AKI, but also in maintaining it $^{50}$. Also, the early inflammatory response in IRI consists mainly of neutrophils, which generate ROS, and are recruited by $\operatorname{ROS}^{51}$.

One study that focused on the pathophysiology of renal IRI showed that pericytes express adhesion protein-1, a key protein that generates a local $\mathrm{H}_{2} \mathrm{O}_{2}$ gradient which further stimulates the neutrophil infiltration ${ }^{52}$, proving that reactive species are directly involved in developing renal injury following ischemia.

Another study concluded that, following renal IRI, Nrf2-regulated cell defense genes presented significantly high levels in the kidneys of wild-type mice but not in Nrf2-knockout $\left(\left(^{-/}\right)\right.$mice $^{53,54}$. The same study showed that the loss of Nrf2 leads to an increase in severity of renal IRI, which also proves that oxidative stress plays a crucial role in the pathogenesis and outcome of renal IRI.

Tracz et $\mathrm{al}^{32,55}$ showed that mice who were heme oxygenase-1 knockout (HO-1/-) had increased sensitivity to renal IRI, and expressed a higher inflammatory response and oxidative damage and an increase in mortality when compared to wild-type mice.

Another study demonstrated that mice deficient in transient receptor potential melastatin 2 (TRPM2) who were subjected to renal IRI showed resistance to OS and apoptosis ${ }^{56}$. TRPM2 is a nonselective cation channel (for calcium, sodium, and potassium) activated by OS, ADP-ribose, TNF- $\alpha$, and intracellular calcium, all of which are considered to be increased in kidney ischemia. Gao et al. showed that TRPM2-knockout mice are resistant to IRI, with a reduction in OS, NADPH oxidase activity, and apoptosis in the kidney. Also, they obtained similar results by pharmacologically inhibiting TRPM2. The cationic channel was identified mainly in the proximal tubule epithelial cells, and Gao et al. showed that its effects are attributable to expression in parenchymal cells. Also, they showed that the activation of RAC1, a constituent of the NADPH oxidase complex, was promoted by TRPM2 following renal ischemia. In contrast, inhibition of RAC1 in vivo reduced ischemic injury and OS. This further shows that OS and ischemic injury are closely interrelated.

\section{Sepsis-induced AKI}

In intensive care units, sepsis represents the major cause of acute kidney injury ${ }^{57}$. Of all the bacterial pathogens that induce AKI, Gram-negative bacteria represent a major threat due to the composition of their outer membrane. One of the main components of their outer membrane is represented by lipopolysaccharide (LPS), an endotoxin considered to be an important trigger of 
278 the inflammatory response in sepsis. These lipopolysaccharides are recognized by Toll-like

279

280

281

282

283

284

285

286

287

288

289

290

291

292

293

294

295

296

297

298

299

300

301

302

303

304

305

306

307

308

309

310

311

312

313

314

315

316

receptor (TLR), a transmembrane protein expressed in renal tubules. Once the LPS bind to TLRs, the immune system is triggered, and the acquired immunity develops an antigen-specific response $\mathrm{e}^{58}$.

TLR4 binds specifically to the LPS ligand, and their binding triggers a cascade of events that leads to OS and a pro-inflammatory response, with new cytokines and mediators being further released. Tumor necrosis factor- $\alpha$ (TNF- $\alpha$ ) and interleukin- $1 \beta$ (IL-1 $1 \beta$ ) are just two of the newly generated molecules which consequently promote the $\mathrm{H}_{2} \mathrm{O}_{2}$ formation, with oxidative damage which further enhances the inflammatory response ${ }^{59}$.

Many studies suggest that both sepsis and ischemia upregulate TLR4 ${ }^{60,61,62}$. Hato et al ${ }^{63}$ studied the effect of endotoxin preconditioning and concluded that it confers renal epithelial protection in vivo, by preventing peroxisomal damage, abolishing OS and tubule injury. Oxidative stress was measured in both preconditioned and nonpreconditioned mice, with measurements performed after 4 hours from LPS inoculation intraperitoneally. High levels of OS were determined in proximal tubules of NP wild-type mice, whereas in preconditioned wild-type mice OS was absent. TLR4 ${ }^{-/}$mice showed no OS, which confirms that TLR4 plays a crucial role in LPS signaling pathway. Also, in preconditioned mice, KIM-1 and NGAL, markers for tubular injury, were significantly reduced, suggesting renal protection. This study proves that sepsis indeed upregulates TRL4, and leads to high levels of OS in renal proximal tubules, with subsequent oxidative damage.

TLR9 identifies bacterial DNA with unmethylated CpG motifs ${ }^{64}$, but the TLR9 pathway is also activated by endogenous mitochondrial DNA (mtDNA) ${ }^{65}$. Tsuji et al. ${ }^{56}$ studied the role of mtDNA via TLR9 in septic AKI and showed that cytokine production, tubular mitochondrial disorders (ATP depletion) and splenic apoptosis are inflicted by the circulating mtDNA released in the early phase of sepsis. They used an animal model of sepsis in wild-type and TLR9-/- mice, but they also injected mitochondrial debris intravenously. The results show that TLR9-/ mice presented a lower bacteremia than wild-type mice, but with a higher level of leucocyte migration. Also, TLR9 ${ }^{-/}$mice presented lower levels of IFN- $\gamma$ and IL-12 than wild-type mice, with attenuated production of superoxide in the proximal tubule cells. When injected with mitochondrial debris containing a substantial amount of mtDNA, wild-type mice had increased plasma levels of IL-12, but not of IFN- $\gamma$ and TNF- $\alpha$, while the levels of IL-12 in TLR9 ${ }^{-/-}$mice did not increase as much. This study further shows that sepsis upregulates certain receptors that stimulate the production of reactive species and oxidative damage.

While sepsis remains ubiquitous, aforementioned studies suggest that the cascade of events that it triggers, including oxidative stress damage and inflammatory response, could be counteracted at receptor level. More studies are needed in order to gain a better perspective of how OS could be addressed in sepsis-induced AKI.

\section{How do the kidneys combat oxidative stress?}

Peer] reviewing PDF | (2019:06:38777:1:1:NEW 8 Oct 2019) 
317 Homeostasis is favored by balancing the production of both oxidants and antioxidants. It has 318 been proved that ROS play a physiological role in renal function, but when reactive species are 319 unregulated or upregulated with consequent local accumulation, they are able to induce OS, 320 irreversibly damaging DNA, RNA, lipids, proteins, causing organelle dysfunctionality ${ }^{66}$. The 321 oxidant production is usually counterbalanced by formation of endogenous antioxidants which 322 disrupt the damaging effects of OS. High levels of ROS may overrun the antioxidant activity, 323 promoting dysfunction of the vasculature, triggering an inflammatory response, with consequent 324 cytotoxicity on renal tubule cells, mechanisms that are observed in the pathogenesis of $\mathrm{AKI}^{21}$. 325 Antioxidants represent the body's system to combat the reactive species that are constantly 326 released inside the cell ${ }^{19}$. They are molecules that intervene early in AKI development, by scavenging reactive species. There are several antioxidant systems able to protect the renal cells from $\mathrm{OS}^{21}$. Exogenous antioxidants are mainly represented by dietary and/or supplementation substances which downregulate OS, consequently diminishing lipid peroxidation, and oxidative damage ${ }^{66}$. Table 2 contains the main antioxidants that can be found in the renal tissue.

Modulating AKI with the help of antioxidants represents a focus point for many human and animal studies ${ }^{67}$, which have shown that nephrotoxicity and renal ischemia induce an increased oxidative damage with low levels of local antioxidants ${ }^{68,69}$.

Superoxide dismutase (SOD) isoforms represent some of the major enzymes that fight against OS, and they all can be found in the kidneys. They are localized in both the extracellular space, and intracellular space (mitochondria, cytoplasm). SOD localization varies by species, but their renal activity is comparable in human, mouse, sheep, etc ${ }^{70}$. SOD is a catalysator that helps the dismutation of $\mathrm{O}_{2}^{-}$into $\mathrm{O}_{2}$ and $\mathrm{H}_{2} \mathrm{O}_{2}$. It is considered to be the first system to fight $\mathrm{OS}^{21}$. SOD1 (copper/zinc form of SOD) cannot be found inside the mitochondria, but is commonly present in other intracellular spaces. It is responsible for $80 \%$ of the activity that SOD has in the renal tissues ${ }^{71}$, and for $1 / 3$ of the SOD activity in the renal vasculature, where it stops disruption of NO signaling ${ }^{72}$. SOD1 suppresses the clearing of nitric oxide by $\mathrm{O}_{2}$-inside the cellular compartments, maintaining the production of $\mathrm{H}_{2} \mathrm{O}_{2}{ }^{21}$.

SOD2 (manganese form of SOD) is present in great quantities inside the mitochondria, and it plays a key role in generating and releasing the peroxide from the mitochondria. ONOO- is able to inactivate SOD2. Overexpression of this isoform, but not catalase, ameliorates AKI induced by cisplatin in vitro ${ }^{73}$, fact that shows the importance of superoxide anion in $\mathrm{AKI}^{52}$. One study in which SOD2 and SOD1 were ablated in mice, showed that the pathological phenotype was aggravated in SOD2-ablated mice, despite the fact that SOD1 is responsible for most of the SOD activity ${ }^{74}$. This data suggests that the localization of reactive species is of great importance, indicating that mitochondria is crucial in the initiation and evolution of $\mathrm{AKI}^{21}$. SOD3 is an extracellular copper/zinc SOD isoform responsible for protecting nitric oxide from $\mathrm{O}_{2}{ }^{-}$, and also for converting $\mathrm{O}_{2}{ }^{-}$into $\mathrm{H}_{2} \mathrm{O}_{2}$ in the extracellular environment ${ }^{21}$.

SOD mimetic activity can be found in pharmacologic agents Tempol and MnTMPyP which have proved to ameliorate both ischemia-induced AKI, and sepsis-induced $\mathrm{AKI}^{75}{ }^{76}$. Also, MnTMPyp 
356 (which is both SOD and catalase mimetic) decreases SOD related to renal fibrosis after ischemic $357 \quad \mathrm{AKI}^{77}$.

358 Catalase, an enzyme containing heme, is responsible for further converting $\mathrm{H}_{2} \mathrm{O}_{2}$ into $\mathrm{O}_{2}$ and $359 \mathrm{H}_{2} \mathrm{O}$, without requiring additional cofactors ${ }^{21}$. It is ubiquitary in cells with aerobic metabolism, 360 and high levels of catalase are found in renal cells ${ }^{78}$. Intracellular disposition shows that catalase 361 is mainly found in the cytosol and in peroxisomes ${ }^{21}$. Its deficiency leads to ROS accumulation 362 inside the mitochondrial matrix, causing mitochondrial dysfunction ${ }^{79}$. An experimental study of 363 endotoxemia in mice showed that LPS can downregulate the catalase activity, aggravating renal 364 damage $^{80}$.

365 Thioredoxin peroxidase systems also consume $\mathrm{H}_{2} \mathrm{O}_{2}$, while oxidizing thioredoxin. The oxidized 366 forms that result play a crucial role in several signaling mechanisms. These peroxidases can be 367 found in most cellular compartments ${ }^{21}$.

368 Glutathione and glutathione peroxidase family are present in all cellular compartments 369 (including the nucleus, mitochondria, cytoplasm) ${ }^{46,66,81}$. Glutathione is important for regulating 370 the cellular redox, while being a part of the controlling mechanisms responsible for the cellular proliferation, DNA synthesis, and cellular apoptosis ${ }^{82}$. In the mitochondria, glutathione regulates apoptosis and necrosis, while in the nucleus it modulates the cellular division ${ }^{66}$.

Edaravone represents an approved stroke therapy in Japan. It has been studied in multiple experimental models, and it has been shown that it reduces the generation of ROS in vitro in the renal tubular cells, reduces lipid peroxidation in vivo ${ }^{52}$, improves kidney function in rats with $\mathrm{IRI}^{83}$, and also in rats with nephrotoxicity ${ }^{84}$. These results show that edaravone (norphenazone, MCI-186) might be able to avoid preservation injury in kidney transplantation ${ }^{52}$. Vitamin $C$ is a well-known antioxidant that attenuates OS, inflammation and improves kidney function in AKI animal models (ischemia-induced, chemically-induced, rhabdomyolysis-induced $\mathrm{AKI})^{52}$. Vitamin $\mathrm{C}$ plays an important role for some enzymatic reactions as a cofactor, participating in several defense mechanisms. Vitamin $\mathrm{C}$ redox is preserved by diverse components of redox systems in the cell, reacting with oxidized forms of molecules (enzymes, free radicals $)^{21}$.

Selenium $(\mathrm{Se})$ represents a trace element that plays a role in cellular aerobic respiration by reducing free radicals ${ }^{85}$. Selenium deficiency was linked to AKI in rodent model ${ }^{86}$. Also, several experimental studies showed improved kidney function after Se supplementation in AKI induced by cisplatin ${ }^{71}$, and by gentamycin ${ }^{87}$. Selenium upregulated antioxidants in a pig model of transplanted kidneys (ischemia-reperfusion injury) ${ }^{88}$.

Sulforaphane, a natural dietary isothiocyanate, has been shown to be renoprotective and able to improve kidney function in an animal renal IRI model ${ }^{89}$. In this study, Shokeir et al showed that ischemic preconditioning and sulforaphane both enhanced gene expression ( $\mathrm{Nrf} 2$, heme oxygenase-1 HO-1, NADPH-quinone oxidoreductase1 NQO-1) and diminished the inflammatory (TNF- $\alpha$, IL-1, ICAM-1) and apoptotic markers (caspase-3), with better results for sulforaphane alone. Their combination improved the antioxidant gene expression and attenuated the inflammatory genes. 
396

397

398

399

400

401

402

403

404

405

406

407

408

409

410

411

412

413

414

415

416

417

418

419

420

421

422

423

424

425

426

427

428

429

430

431

432

433

434

435

Antioxidants play a leading role in fighting oxidative stress and preventing oxidative damage. Both endogenous and exogenous (dietary/supplementation) seem to have a beneficial impact on renal function, with renoprotective effects and good outcomes even on the suffering kidneys.

\section{Are there any biomarkers for detecting oxidative stress in early AKI?}

The interest in defining biomarkers for acute illnesses is continuously increasing. Recent studies focused on molecules that might increase specifically in OS. Some of them, conducted in patients who suffered kidney damage induced by sepsis or by other critically illnesses, highlighted the presence of plasmatic biomarkers from protein and lipid oxidation that could be correlated with other markers for cytokines, pro-oxidative mediators and pro-inflammatory markers ${ }^{20}$. Ischemia causes alterations in DNA structure and leads to lipids peroxidation, leading to increased levels of 3-nitrotyrosine, a well-known biomarker for ROS and RNS ${ }^{90,91}$.

One study showed that renal IRI causes increased urinary expression of thioredoxin1 (TRX), making it a possible biomarker for $\operatorname{OS}^{32,92}$.

Costa et $\mathrm{al}^{93}$ conducted a study in septic shock patients admitted to the Intensive Care Unit (ICU) and determined the protein carbonyl concentration upon admission. The levels of protein carbonyl were significantly higher in patients who developed septic AKI, and they were also positively correlated with the SOFA score. Moreover, protein carbonyl concentration was associated with development of septic AKI, and with mortality in these critical patients. This study shows a novel molecule that could be used as a biomarker in AKI with excellent reliability. Recently, transfer RNA (tRNA) has been shown to be cleaved into half molecules under OS, resulting tRNA-derived stress-induced fragments (tiRNAs) ${ }^{94}$. Mishima et al ${ }^{95}$ used a specific tRNA-specific modified nucleoside 1-methyladenosine (m1A) antibody to show that changes in RNA structure occur much earlier than DNA damage in OS exposure. Change in tRNA structure leads to further tRNA fragmentation, reflecting early stages of OS damage. Authors suggest that detecting tRNA damage could be a valuable tool for recognizing early organ damage and making a better medical decision.

\section{Conclusions}

Acute kidney injury, although common in clinical practice, is still poorly understood from the pathophysiological point of view. This leads to addressing AKI with only supportive therapies, instead of effective therapeutics to treat it. Research focuses on understanding the molecular pathways that are present in renal injury, but the large possible etiologies of AKI along with other comorbidities that patients might suffer from, make it really problematic to draw a conclusion. Also, animal models used in the experimental studies are more or less comparable to the human body from the physiological and pathophysiological point of view. Recent data shows that oxidative stress plays a crucial role in both initiating and further development of AKI, making it a possible target for therapies. Oxidative damage leading to DNA and RNA alterations, peroxidation of lipids, changes in the structure of proteins, represents an important cause of kidney damage that must be addressed when attempting to treat AKI. ROS, RNS, free radicals 
436 are closely linked to AKI, and they must be very well understood in order to be targeted.

437 Endogenous antioxidants represent a first line against oxidative damage, and their

438 downregulation worsens the outcome in kidney injury. Antioxidant supplementation is intensely

439 studied, showing promising renoprotective effects. Moreover, research focuses on OS

440 biomarkers that can be detected in early phases of AKI, with apparently good results, whether we

441 talk about detecting novel molecules or using newly-constructed monoclonal antibodies.

442 Nonetheless, more studies are needed in order to establish new clinical guidelines.

443 Oxidative stress in acute kidney injury, although accepted as a key component in the pathophysiology of AKI, is yet to be understood as a target for novel therapeutics.

\section{Acknowledgements}

447 None.

448

449

\section{References}

1 Chawla LS, Eggers PW, Star RA, Kimmel PL. Acute kidney injury and chronic kidney disease as interconnected syndromes. N Engl J Med 2014;371:58-66.

452 2 He L, Wei Q, Liu J, Yi M, Liu Y, Liu H, Sun L, Peng Y, Liu F, Venkatachalam MA, Dong Z. AKI on CKD: heightened injury, suppressed repair, and the underlying mechanisms. Kidney Int 2017;92:1071-1083. 3 Mehta RL, Chertow GM. Acute renal failure definitions and classification: time for change?. JASN 2003; 14(8):2178-87.

4564 Bellomo R, Ronco C, Kellum JA, Mehta RL, Palevsky P. Acute renal failure - definition, outcome measures, animal models, fluid therapy and information technology needs: the second international consensus conference of the acute dialysis quality initiative (ADQI ) group. Critical Care 2004;8(4):204-12. 5 Palevsky PM1, Liu KD, Brophy PD, Chawla LS, Parikh CR, Thakar CV, Tolwani AJ, Waikar SS, Weisbord SD. KDOQI US commentary on the $2012 \mathrm{KDIGO}$ clinical practice guideline for acute kidney injury. AJKD 2013;61(5):649-672.

4626 Susantitaphong P, Cruz DN, Cerda J, Abulfaraj M, Alqahtani F, Koulouridis I, Jaber BL; Acute Kidney Injury Advisory Group of the American Society of Nephrology. Acute Kidney Injury Advisory Group of the American Society of N: World incidence of AKI: a meta-analysis. Clin J Am Soc Nephrol 2013;8:1482-1493.

465 7 Ostermann M, Chang RW. Acute kidney injury in the intensive care unit according to RIFLE. Critical Care Medicine 2007;35(8):1837-1843.

4678 Bagshaw SM, George C, Dinu I, Bellomo R. A multicentre evaluation of the RIFLE criteria for early acute kidney injury in critically ill patients. NDT 2008;23(4):1203-1210.

4699 Lameire NH, Bagga A, Cruz D, De Maeseneer J, Endre Z, Kellum JA, Liu KD, Mehta RL, Pannu N, Van Biesen W, Vanholder R. Acute kidney injury: an increasing global concern. Lancet 2013;382:170-179. 10 Wald R, Quinn RR, Luo J, Li P, Mamdani MM, Ray JG; University of Toronto Acute Kidney Injury Research Group. Chronic dialysis and death among survivors of acute kidney injury requiring dialysis. JAMA 2009;302:1179-1185.

47411 Basile DP, Bonventre JV, Mehta R, Nangaku M, Unwin R, Rosner MH, Kellum JA, Ronco C, ADQI XIII 475 Work Group. Understanding maladaptive repair processes to predict and identify therapeutic treatments. 476 J Am Soc Nephrol 2016;27:687-697.

47712 Agarwal A, Dong Z, Harris R, Murray P, Parikh SM, Rosner MH, Kellum JA, Ronco C, Acute Dialysis 478 Quality Initiative XIII Working Group. Cellular and molecular mechanisms of AKI. J Am Soc Nephrol 479 2016;27:1288-1299. 
48013 Takaori K, Nakamura J, Yamamoto S, Nakata H, Sato Y, Takase M, Nameta M, Yamamoto T, 481 Economides AN, Kohno K, Haga H, Sharma K, Yanagita M. Severity and frequency of proximal tubule injury 482 determines renal prognosis. J am Soc Nephrol 2016;27:2393-2406.

48314 Tanaka S, Tanaka T, Nagaku M. Hypoxia as a key player in the AKI-to-CKD transition. Am J Physiol Renal 484 Physiol 2014;307:F1187-1195.

48515 Ruiz S, Pergola PE, Zager RA, Vaziri ND. Targeting the transcription factor Nrf2 to ameliorate oxidative 486 stress and inflammation in chronic kidney disease. Kidney Int 2013;83:1029-1041.

48716 Nezu M, Souma T, Yu L, Suzuki T, Saigusa D, Ito S, Suzuki N, Yamamoto M. Transcription factor Nrf2 488 hyperactivation in early-phase renal ischemia-reperfusion injury prevents tubular damage progression. 489 Kidney Int 2017;91:387-401.

49017 Halliwell, B. Reactive Species and Antioxidants. Redox Biology Is a Fundamental Theme of Aerobic Life. 491 Plant Physiol 2006;141:312-322.

49218 Valko M, Leibfritz D, Moncol J, Cronin MT, Mazur M, Telser J. Free radicals and antioxidants in normal 493 physiological functions and human disease. Int J Biochem Cell Biol 2007;39:44-84.

49419 Singh A, Kukreti R, Saso L, Kukreti S. Oxidative stress: A key Modulator in Neurodegenerative Diseases. 495 Molecules 2019;24:1583.

49620 Himmelfarb J, McMonagle E, Freedman S, Klenzak J, McMenamin E, Le P, Pupim LB, Ikizler TA, The 497 PICARD Group. Oxidative stress is increased in critically ill patients with acute renal failure. J Am Soc 498 Nephrol 2004;15:2449-2456.

49921 Ratliff BB, Abdulmahdi W, Pawar R, Wolin MS. Oxidant Mechanisms in Renal Injury and Disease. 500 Antioxid Redox Signal 2016;25:119-146.

50122 Carlstrom M, Wilcox CS, Arendshorst WJ. Renal autoregulation in health and disease. Physiol Rev 502 2015;95:405-511.

50323 Just A. Nitric oxide and renal autoregulation. Kidney Blood Press Res 1997;20:201-204.

50424 Loutzenhiser RD, Griffin K, Williamson G, Bidani A. Renal autoregulation: new perspectives regarding 505 the protective and regulatory roles of the underlying mechanisms. Am J Physiol Regul Integr Comp Physiol 506 2006;290:R1153-R1167.

50725 Navar LG, Arendhorst WJ, Bell PD, Imig JD, Inscho EW, Pallone TL. Renal microcirculation In: Handbook 508 of Physiology: Microcirculation, edited by Tuma RF, Duran WN, and Ley K. Academic, 2008. P. 550-683.

50926 Baylis C, Qiu C. Importance of nitric oxide in the control of renal hemodynamics. Kidney Int 510 1996;48:1727-1731.

51127 Majid DSA, Williams A, Navar LG. Inhibition of nitric oxide synthesis attenuates pressure-induced 512 natriuretic response in anaesthetized dogs. Am J Phys 1993;264:F79-F87.

51328 Deng A, Baylis C. Locally produced EDRF controls preglomerular resistance and ultrafiltration 514 coefficient. Am J Phys 1993;264:F212-F215.

51529 Kiyomoto H, Matsuo H, Tamaki T, Aki Y, Hong H, Iwao H, Abe Y.. Effect of L-NG-nitro-arginine, inhibitor 516 of nitric oxide synthesis, on autoregulation of renal blood flow in dogs. Japan J Pharmacol 1992;58:147517155.

51830 Kumagai K, Suzuki H, Ichikawa M, Jimbo M, Murakami M, Ryuzaki M, Ryuzaki M, Saruta T. Nitric oxide 519 increased renal blood flow by interacting with the sympathetic nervous system. Hypertension $5201994 ; 24: 220-226$.

52131 Brown GC. Nitric oxide regulates mitochondrial respiration and cell functions by inhibiting cytochrome 522 oxidase. FEBS Lett 1995;369:136-139.

52332 Piantadosi CA, Suliman HB. Mitochondrial transcription factor A induction by redox activation of 524 nuclear respiratory factor 1. J Biol Chem 2006;281:324-333.

52533 Guzy RD, Hoyos B, Robin E, Chen H, Liu L, Mansfield KD, Simon MC, Hammerling U, Schumacker PT. 526 Mitochondrial complex III is required for hypoxiainduced ROS production and cellular oxygen sensing. Cell 527 Metab 2005;1:401-408. 
52834 Nangaku M, Eckardt KU. Hypoxia and the HIF system in kidney disease. J Mol Med (Berl) 2007;85: 529 1325-1330.

53035 Ruiz S, Pergola PE, Zager RA, Vaziri ND. Targeting the transcription factor Nrf2 to ameliorate oxidative 531 stress and inflammation in chronic kidney disease. Kidney Int 2013;83:1029-1041.

53236 Haque MZ, Majid DS. Assessment of renal functional phenotype in mice lacking gp91PHOX subunit of 533 NAD(P)H oxidase. Hypertension 2004;43:335-340.

53437 Basile DP, Anderson MD, Sutton TA. Pathophysiology of acute kidney injury. Compr Physiol 535 2012;2:1303-1353.

53638 Andrades ME, Morina A, Spasic S, Spasojevic I. Bench-to-bedsidereview: Sepsis-From the redox point 537 of view. Crit Care 2011;15:230.

53839 Duchen MR, Szabadkai G. Roles of mitochondria in human disease. Essays Biochem 2010;47:115-137.

53940 Sureshbabu A, Ryter SW, Choi Me. Oxidative stress and autophagy: Crucial modulators of kidney injury. 540 Redox Biology 2015;4:208-214.

54141 Hall AM, Rhodes GJ, Sandoval RM, Corridon PR, Molitoris BA. In vivo multiphoton imaging of 542 mitochondrial structure and function during acute kidney injury. Kidney Int 2013;83:72-83.

54342 Noiri E, Addabbo F, Goligorsky M. Reactive oxygen and nitrogen species, oxidative and nitrosative 544 stress, and their role in the pathogenesis of acute kidney injury. In: Studies on Renal Disorders, edited by 545 Miyata T, Eckardt K, and Nangaku M. New York: Humana Press, 2011, pp. 161-177.

54643 Yaqoob M, Edelstein CL, Schrier RW. Role of nitric oxide and superoxide balance in hypoxia547 reoxygenation proximal tubular injury. Nephrol Dial Transplant 1996; 11:1738-1742.

54844 Ling H, Edelstein C, Gengaro P, Meng X, Lucia S, Knotek M, Wangsiripaisan A, Shi Y, Schrier R. 549 Attenuation of renal ischemia-reperfusion injury in inducible nitric oxide synthase knockout mice. Am J 550 Physiol 1999;277:F383-F390.

55145 Thomas DD, Heinecke JL, Ridnour LA, Cheng RY, Kesarwala AH, Switzer CH, McVicar DW, Roberts DD, 552 Glynn S, Fukuto JM, Wink DA, Miranda KM. Signaling and stress: The redox landscape in NOS2 biology. 553 Free Radic Biol Med 2015; 87:204-225.

55446 Araujo M, Welch WJ. Oxidative stress and nitric oxide in kidney function. Curr Opin Nephrol Hypertens 555 2006;15:72-77.

55647 Bogdan C. Nitric oxide and the regulation of gene expression. Trends Cell Biol 2001;11:66-75.

55748 Zweier JL, Flaherty JT, Weisfeldt ML. Direct measurement of free radical generation following 558 reperfusion of ischemic myocardium. Proc Natl Acad Sci U S A 1987;84:1404-1407.

55949 Chouchani ET, Pell VR, James AM, Work LM, Saeb-Parsy K, Frezza C, Krieg T, Murphy MP. A unifying 560 mechanism for mitochondrial superoxide production during ischemia-reperfusion injury. Cell Metab 561 2016;23:254-263.

56250 Nath KA, Norby SM. Reactive oxygen species and acute renal failure. Am J Med 2000;109:665-678.

56351 Friedewald JJ, Rabb H. Inflammatory cells in ischemic acute renal failure. Kidney Int 2004;66:486-491.

56452 Tanaka S, Tanaka T, Kawakami T, Takano H, Sugahara M, Saito H, Higashijima Y, Yamaguchi J, Inagi R, 565 Nangaku M. Vascular adhesion protein- 1 enhances neutrophil infiltration by generation of hydrogen 566 peroxide in renal ischemia/reperfusion injury. Kidney Int 2017;92:154-164.

56753 Leonard MO, Kieran NE, Howell K, Burne MJ, Varadarajan R, Dhakshinamoorthy S, Porter AG, O'Farrelly $568 \mathrm{C}$, Rabb H, Taylor CT. Reoxygenation-specific activation of the antioxidant transcription factor Nrf2 569 mediates cytoprotective gene expression in ischemia- reperfusion injury. FASEB J 2006;20:2624-2626.

57054 Liu M, Grigoryev DN, Crow M, Haas M, Yamamoto M, Reddy SP, Rabb H. Transcription factor Nrf2 is 571 protective during ischemic and nephrotoxic acute kidney injury in mice. Kidney Int 2009;76:277-285.

57255 Tracz MJ, Juncos JP, Croatt AJ, Ackerman A, Grande JP, Knutson KL, Kane GC, Terzic A, Griffin MD, Nath 573 KA. Deficiency of heme oxygenase-1 impairs renal hemodynamics and exaggerates systemic inflammatory 574 responses to renal ischemia. Kidney International 2007; 72(9):1073-1080. 
575

576

577

578

579

580

581

582

583

584

585

586

587

588

589

590

591

592

593

594

595

596

597

598

599

600

601

602

603

604

605

606

607

608

609

610

611

612

613

614

615

616

617

618

619

620

56 Gao G, Wang W, Tadagavadi RK, Briley NE, Love MI, Miller BA, Reeves WB. TRPM2 mediates ischemic kidney injury and oxidant stress through RAC1. Journal of Clinical Investigation 2014; 124(11):4989-5001.

57 Uchino S, Kellum JA, Bellomo R, Doig GS, Morimatsu H, Morgera S, Schetz M, Tan I, Bouman C, Macedo E, Gibney N, Tolwani A, Ronco C. Acute renal failure in critically ill patients: a multinational, multicenter study. JAMA 2005;294:813-818.

58 Medzhitov R. Toll- like receptors and innate immunity. Nat Rev Immunol 2001;1:135-145.

$59 \mathrm{Li}$ Q, Engelhardt JF. Interleukin-1beta induction of NFkappaB is partially regulated by $\mathrm{H} 2 \mathrm{O} 2$ - mediated activation of NFkappaB- inducing kinase. J Biol Chem 2006;281:1495-1505.

60 Wu H, Chen G, Wyburn KR, Yin J, Bertolino P, Eris JM, Alexander SI, Sharland AF, Chadban SJ. TLR4 activation mediates kidney ischemia/reperfusion injury. J Clin Invest 2007;117:2847-2859.

61 Pulskens WP, Teske GJ, Butter LM, Roelofs JJ, van der Poll T, Florquin S, Leemans JC. Toll-like receptor4 coordinates the innate immune response of the kidney to renal ischemia/reperfusion injury. PLoS ONE 2008;3:e3596.

62 El-Achkar TM, Huang X, Plotkin Z, Sandoval RM, Rhodes GJ, Dagher PC. Sepsis induces changes in the expression and distribution of Toll-like receptor 4 in the rat kidney. Am J Physiol Renal Physiol 2006;290:F1034-1043.

63 Hat T, Winfree S, Kalakeche R, Dube S, Kumar R, Yoshimoto M, Plotkin Z, Dagher PC. The macrophage mediates the renoprotective effects of endotoxin preconditioning. J Am Soc Nephrol 2015;26:1347-1362.

64 Tsuji N, Tsuji T, Ohashi N, Kato A, Fujigaki Y, Yasuda H. Role of mitochondrial DNA in septic AKI via TollLike Receptor 9. J Am Soc Nephrol 2016;27:2009-2020.

65 Zhang Q, Itagaki K, Hauser CJ : Mitochondrial DNA is released by shock and activates neutrophils via p38 map kinase. Shock 2010; 34:55-59.

66 Dennis JM, Witting PK. Protective Role for Antioxidants in Acute Kidney Disease. Nutrients 2017;9:718.

67 Chatterjee PK. Novel pharmacological approaches to the treatment of renal ischemia-reperfusion injury: A comprehensive review. Naunyn Schmiedebergs Arch Pharmacol 2007;376:1-43.

68 Paller MS, Hoidal JR, Ferris TF. Oxygen free radicals in ischemic acute renal failure in the rat. J Clin Investig 1984;74:1156-1164.

69 Baliga R, Ueda N, Walker PD, Shah SV. Oxidant mechanisms in toxic acute renal failure. Drug Metab Rev 1999;31:971-997.

70 Marklund SL. Extracellular superoxide dismutase and other superoxide dismutase isoenzymes in tissues from nine mammalian species. Biochem J 1984;222:649-655.

71 Mates JM. Effects of antioxidant enzymes in the molecular control of reactive oxygen species toxicology. Toxicology 2000;153: 83-104.

72 Carlstrom M, Lai EY, Ma Z, Steege A, Patzak A, Eriksson UJ, Lundberg JO, Wilcox CS, Persson AE. Superoxide dismutase 1 limits renal microvascular remodeling and attenuates arteriole and blood pressure responses to angiotensin II via modulation of nitric oxide bioavailability. Hypertension 2010;56: 907-913.

73 Davis CA, Nick HS, Agarwal A. Manganese superoxide dismutase attenuates cisplatin-induced renal injury: Importance of superoxide. J Am Soc Nephrol 2001;12:2683-2690.

74 Schieber M, Chandel NS. ROS function in redox signaling and oxidative stress. Curr Biol 2014;24:R453R462.

75 Chatterjee PK, Cuzzocrea S, Brown PA. Tempol, a membrane-permeable radical scavenger, reduces oxidant stress-mediated renal dysfunction and injury in the rat. Kidney Int 2000;58:658-673.

76 Liang HL, Hilton G, Mortensen J, Regner K, Johnson CP, Nilakantan V. Mntmpyp, a cell-permeant sod mimetic, reduces oxidative stress and apoptosis following renal ischemia-reperfusion. Am J Physiol Ren Physiol 2009;296:F266-F276.

Peer) reviewing PDF | (2019:06:38777:1:1:NEW 8 Oct 2019) 
621

622

623

624

625

626

627

628

629

630

631

632

633

634

635

636

637

638

639

640

641

642

643

644

645

646

647

648

649

650

651

652

653

654

655

656

657

658

659

660

661

662

663

664

665

666

667
76 Kim J, Seok YM, Jung KJ, Park KM. Reactive oxygen species/oxidative stress contributes to progression of kidney fibrosis following transient ischemic injury in mice. Am J Physiol Ren Physiol 2009;297:F461F470.

78 Deisseroth A, Dounce AL. Catalase: physical and chemical properties, mechanism of catalysis, and physiological role. Physiol Rev 1970;50:319-375.

79 Hwang I, Lee J, Huh JY, Park J, Lee HB, Ho YS, Ha H. Catalase deficiency accelerates diabetic renal injury through peroxisomal dysfunction. Diabetes 2012;61:728-738.

80 Vasko R, Ratliff BB, Bohr S, Nadel E, Chen J, Xavier S, Chander P, Goligorsky MS. Endothelial peroxisomal dysfunction and impaired pexophagy promotes oxidative damage in lipopolysaccharideinduced acute kidney injury. Antioxid Redox Signal 2013;19:211-230.

81 Oberley TD, Verwiebe E, Zhong W, Kang SW, Rhee SG. Localization of the thioredoxin system in normal rat kidney. Free Radic Biol Med 2001;30:412-424.

82 Fukai T. Mitochondrial thioredoxin: novel regulator for NADPH oxidase and angiotensin II-induced hypertension. Hypertension 2009;54:224-225.

83 Doi K, Suzuki Y, Nakao A, Fujita T, Noiri E. Radical scavenger edaravone developed for clinical use ameliorates ischemia/reperfusion injury in rat kidney. Kidney Int 2004;65:1714-1723.

84 Satoh M, Kashihara N, Fujimoto S, Horike H, Tokura T, Namikoshi T, Sasaki T, Makino H. A novel free radical scavenger, edarabone, protects against cisplatin-induced acute renal damage in vitro and in vivo. J Pharmacol Exp Ther 2003;305:1183-1190.

85 Aksoy A, Karaoglu A, Akpolat N, Naziroglu M, Ozturk T, Karagoz ZK. Protective Role of Selenium and High Dose Vitamin E against Cisplatin - Induced Nephrotoxicty in Rats. Asian Pacific Journal of Cancer Prevention. 2015;16(16):6877-82.

86 Iglesias P, Selgas R, Romero S, Diez JJ. Selenium and kidney disease. J Nephrol 2013;26:266-272.

87 Randjelovic P, Veljkovic S, Stojiljkovic N, Velickovic L, Sokolovic D, Stoiljkovic M, Ilic I. Protective effect of selenium on gentamicin-induced oxidative stress and nephrotoxicity in rats. Drug Chem Toxicol 2012;35:141-148.

88 Treska V, Kuntscher V, Hasman D, Neprasová P, Kobr J, Racek J, Trefil L, Hes O. Importance of selenium for the influence of ischemia-reperfusion syndrome after kidney transplantation from a non-heart beating donor in a pig model. Transplant Proc 2002;34:3057-3059.

89 Shokeir AA, Barakat N, Hussein AM, Awadalla A, Harraz AM, Khater S, Hemmaid K, Kamal Al. Activation of Nrf2 by ischemic preconditioning and sulforaphane in renal ischemia/reperfusion injury: a comparative experimental study. Physiol Res 2015;64:313-323.

90 Noiri E, Nakao A, Uchida K, Tsukahara H, Ohno M, Fujita T, Brodsky S, Goligorsky MS. Oxidative and nitrosative stress in acute renal ischemia. Am J Physiol. Ren Physiol. 2001;281:F948-F957.

91 Walker LM, York JL, Imam SZ, Ali SF, Muldrew KL, Mayeux PR. Oxidative stress and reactive nitrogen species generation during renal ischemia. Toxicol Sci 2001;63:143-148

92 Kasuno K, Shirakawa K, Yoshida H, Mori K, Kimura H, Takahashi N, Nobukawa Y, Shigemi K, Tanabe S, Yamada N, Koshiji T, Nogaki F, Kusano H, Ono T, Uno K, Nakamura H, Yodoi J, Muso E, Iwano M. Renal redox dysregulation in AKI: application for oxidative stress marker of AKI. Am J of Physiol. Ren Physiol. 2014;307(12):F1342-F1351.

93 Costa NA, Gut AL, Azevedo PS, Tanni SE, Cunha NB, Fernandes AAH, Polegato BF, Zornoff LAM, de Paiva SAR, Balbi AL, Ponce D, Minicucci MF. Protein carbonyl concentration as a biomarker for development and mortality in sepsis-induced acute kidney injury. Bioscience Reports 2018; BSR20171238. 94 Yamasaki S, Ivanov P, Hu GF, Anderson P. Angiogenin cleaves tRNA and promotes stress-induced translational repression. J cell Biol 2009;185:35-42.

95 Mishima E, Inoue C, Saigusa D, Inoue R, Ito K, Suzuki Y, Jinno D, Tsukui Y, Akamatsu Y, Araki M, Araki K, Shimizu R, Shinke H, Suzuki T, Takeuchi Y, Shima H, Akiyama Y, Toyohara T, Suzuki C, Saiki Y, Tominaga T,

Peer) reviewing PDF | (2019:06:38777:1:1:NEW 8 Oct 2019) 
668 Miyagi S, Kawagisihi N, Soga T, Ohkubo T, Yamamura K, Imai Y, Masuda S, Sabbisetti V, Ichimura T, Mount 669 DB, Bonventre JV, Ito S, Tomioka Y, Itoh K, Abe T. Conformational change in transfer RNA is an early 670 indicator of acute cellular damage. J aM Soc Nephrol 2014;25:2316-2326. 
Table $\mathbf{1}$ (on next page)

The main reactive species in AKI 
1 Table 1. The main reactive species in AKI

\begin{tabular}{|c|c|c|c|c|c|}
\hline $\begin{array}{l}\text { Superoxide } \\
\text { anion }^{21,28,29,37}\end{array}$ & $\mathrm{O}_{2}^{-}$ & $\begin{array}{l}\text { Induced by NOX, } \\
\text { XO and other } \\
\text { enzymes } \\
\text { Generated by the } \\
\text { mitochondrial } \\
\text { respiratory chain }\end{array}$ & $\begin{array}{l}\text { Maintains a } \\
\text { physiological role in } \\
\text { the renal vasculature }\end{array}$ & $\begin{array}{l}\text { Generates other ROS } \\
\text { (e.g. forms } \mathrm{H}_{2} \mathrm{O}_{2} \text { via } \\
\text { dismutation) } \\
\text { Scavenges } \mathrm{NO} \\
\text { Disrupts the iron- } \\
\text { sulfur centers }\end{array}$ & $\begin{array}{l}\text { In sepsis- } \\
\text { induced AKI, } \\
\mathrm{O}_{2}^{-} \text {is } \\
\text { generated by } \\
\text { immune cells }\end{array}$ \\
\hline $\begin{array}{l}\text { Hydrogen } \\
\text { peroxide }^{21,66}\end{array}$ & $\mathrm{H}_{2} \mathrm{O}_{2}$ & $\begin{array}{l}\text { Generated by } \\
\text { dismutation } \\
\text { Generated by } \\
\text { oxidases from } \\
\text { molecular oxygen }\end{array}$ & & $\begin{array}{l}\text { Diffuses across } \\
\text { biological membranes } \\
\text { to other cellular } \\
\text { compartments and } \\
\text { other cells } \\
\text { Reacts with iron- } \\
\text { containing molecules, } \\
\text { releasing additional } \\
\text { ROS }\end{array}$ & \\
\hline $\begin{array}{l}\text { Hydroxyl } \\
\text { radical }^{31,47,66}\end{array}$ & $\mathrm{HO}^{-}$ & $\begin{array}{l}\text { Generated by } \\
\text { Fenton reaction }\end{array}$ & & $\begin{array}{l}\text { Lipid peroxidation, } \\
\text { with subsequent } \\
\text { membrane damage } \\
\text { Generates additional } \\
\text { ROS }\end{array}$ & \\
\hline $\begin{array}{l}\text { Hypochlorous } \\
\text { acid }^{21,29}\end{array}$ & $\mathrm{HClO}$ & $\begin{array}{l}\text { Generated by } \\
\text { MPO in } \\
\text { inflammatory cells }\end{array}$ & & $\begin{array}{l}\text { Lipid soluble } \\
\text { molecule } \\
\text { Reacts with amines, } \\
\text { producing } \\
\text { chloroamines }\end{array}$ & \\
\hline Peroxynitrite $^{21}$ & $\mathrm{ONOO}^{-}$ & $\begin{array}{l}\text { Generated from } \\
\text { nitric oxide } \\
\text { reacting with } \\
\text { superoxide anion } \\
\text { Generated by } \\
\text { heme peroxidase } \\
\text { enzymes from the } \\
\text { nitrate metabolism }\end{array}$ & $\begin{array}{l}\text { Major inhibitor of the } \\
\text { mitochondrial } \\
\text { respiration chain }\end{array}$ & $\begin{array}{l}\text { Oxidizes or nitrates } \\
\text { thiols } \\
\text { Oxidizes and nitrates } \\
\text { fatty acid } \\
\text { Irreversibly disrupts } \\
\text { the centers of iron- } \\
\text { sulfur }\end{array}$ & \\
\hline $\begin{array}{l}\text { Nitric } \\
\text { oxide }^{21,22,29,30,31,44}\end{array}$ & $\mathrm{NO}$ & $\begin{array}{l}\text { Generated by } \\
\text { eNOS and eNOS }\end{array}$ & $\begin{array}{l}\text { Vasodilator and } \\
\text { counteracts renal } \\
\text { vasoconstriction } \\
\text { Modulates the } \\
\text { myogenic response } \\
\text { Protects endothelial } \\
\text { and mesangial cells } \\
\text { from fibrosis and } \\
\text { apoptosis } \\
\text { Induces antioxidative } \\
\text { genes } \\
\text { Inhibits cyt-c oxidase } \\
\text { and alters the } \\
\text { generation of ROS in }\end{array}$ & $\begin{array}{l}\text { Soluble gas } \\
\text { Larger levels of NO } \\
\text { interact with bound } \\
\text { iron, and produce } \\
\text { NO-derived RNS that } \\
\text { can nitrosate thiols }\end{array}$ & $\begin{array}{l}\text { Mice } \\
\text { deficient in } \\
\text { iNOS were } \\
\text { resistant to } \\
\text { renal IRI }\end{array}$ \\
\hline
\end{tabular}


the mitochondria

Binds to guanylate

cyclase and regulates

the production of

cGMP 
Table 2 (on next page)

The main antioxidants fighting oxidative stress in AKI 
1 Table 2. The main antioxidants fighting oxidative stress in AKI

\begin{tabular}{|c|c|c|c|c|}
\hline \multirow[t]{3}{*}{$\begin{array}{l}\text { Superoxide } \\
\text { dismutase }\end{array}$} & $\mathrm{SOD}^{21,70,71}$ & $\begin{array}{l}\text { Extracellular } \\
\text { and } \\
\text { intracellular }\end{array}$ & \multicolumn{2}{|c|}{$\begin{array}{l}\text { Catalysator } \\
\text { Generates } \mathrm{O}_{2} \text { and } \mathrm{H}_{2} \mathrm{O}_{2} \text { via dismutation } \\
\text { Considered the first system to fight oxidative stress }\end{array}$} \\
\hline & $\begin{array}{l}\text { SOD1 } 21,71,72 \\
\text { (copper/zinc } \\
\text { isoform) } \\
\text { - dimer }\end{array}$ & Cytoplasm & $\begin{array}{l}\text { Suppresses the clearing } \\
\mathrm{NO} \text {, maintaining the } \\
\text { production of } \mathrm{H}_{2} \mathrm{O}_{2}\end{array}$ & $\begin{array}{l}\text { Gene located on chromosome } 21 \\
(21 \mathrm{q} 22.1)\end{array}$ \\
\hline & $\begin{array}{l}\text { SOD2 } 52,73,74 \\
\text { (manganese } \\
\text { isoform) } \\
\text { - tetramer }\end{array}$ & $\begin{array}{l}\text { Mitochondria } \\
\text { (great } \\
\text { quantities) }\end{array}$ & $\begin{array}{l}\text { Generates and releases } \\
\text { peroxide from the } \\
\text { mitochondria } \\
\text { Inactivated by } \mathrm{ONOO}^{-}\end{array}$ & $\begin{array}{l}\text { Gene located on chromosome } 6 \\
(6 \mathrm{q} 25.3) \\
\text { Overexpression ameliorates cisplatin- } \\
\text { induced AKI in vitro }\end{array}$ \\
\hline Catalase $^{21,78,79,80}$ & $\begin{array}{l}\text { Contains heme } \\
\text { groups with iron } \\
\text { core } \\
\text { - tetramer }\end{array}$ & $\begin{array}{l}\text { Intracellular } \\
\text { (mainly in in } \\
\text { the cytosol } \\
\text { and in } \\
\text { peroxisomes) } \\
\text { In cells with } \\
\text { aerobic } \\
\text { metabolism }\end{array}$ & \multicolumn{2}{|c|}{ Converts $\mathrm{H}_{2} \mathrm{O}_{2}$ into $\mathrm{O}_{2}$ and $\mathrm{H}_{2} \mathrm{O}$} \\
\hline $\begin{array}{l}\text { Thioredoxin } \\
\text { peroxidase } \\
\text { systems } \\
\end{array}$ & & Intracellular & \multicolumn{2}{|c|}{ Converts $\mathrm{H}_{2} \mathrm{O}_{2}$ by oxidizing thioredoxin } \\
\hline Edaravone $^{52,83,84,85}$ & $\begin{array}{l}\text { Norphenazone } \\
\text { MCI- } 186 \\
\text { Synthetic } \\
\text { medication }\end{array}$ & & $\begin{array}{l}\text { Reduces ROS generation } \\
\text { in the renal tubular cells, } \\
\text { in vitro } \\
\text { Reduces lipid } \\
\text { peroxidation, in vivo }\end{array}$ & $\begin{array}{l}\text { Improves kidney function in rats with } \\
\text { IRI, and in rats with nephrotoxicity }\end{array}$ \\
\hline Vitamin $C^{21,52}$ & $\begin{array}{l}\text { Vitamin } \\
\text { Dietary/ } \\
\text { Supplementation } \\
\text { intake }\end{array}$ & & $\begin{array}{l}\text { Reacts with oxidized } \\
\text { forms of enzymes and } \\
\text { free radicals } \\
\text { Cofactor for some } \\
\text { enzymatic reactions }\end{array}$ & $\begin{array}{l}\text { Shown to improve kidney function in } \\
\text { ischemia/ chemically/ } \\
\text { rhabdomyolysis-induced AKI }\end{array}$ \\
\hline Selenium ${ }^{71,80,81,82}$ & Trace element & & $\begin{array}{l}\text { Participates in aerobic } \\
\text { respiration reducing FR } \\
\text { Upregulates antioxidants }\end{array}$ & $\begin{array}{l}\text { Deficiency linked to AKI } \\
\text { Improves kidney function in toxic } \\
\text { AKI }\end{array}$ \\
\hline Sulforaphane $^{79,89}$ & $\begin{array}{l}\text { Isothiocyanate } \\
\text { Dietary intake }\end{array}$ & & & Improves kidney function in renal IRI \\
\hline
\end{tabular}

